\title{
IAWA, IAWS and IUFRO Conference 23-26 June 2010, Madison, WI, USA
}

\author{
John Barnett
}

Published online: 3 January 2010

(C) Springer-Verlag 2010

The International Academy of Wood Science, the Pan-American Regional Group of IAWA, and Division 5 of IUFRO are organizing a joint conference in Madison, WI, USA for June 23-26, 2010. This joint conference will serve as an international forum for the exchange of knowledge and experience in a wide variety of fields including tree biology, systematic wood anatomy and wood identification, paleobotany, ecophysiology, wood formation and cambial activity, and wood quality research. Participants will have the opportunity to discuss their recent research progress, exchange information, and develop collaborations.

The conference will be held in the Memorial Union at 800 Langdon St. located on the shores of Lake Mendota on the University of Wisconsin, Madison campus.

For updates, check the IAWS website http://www.iawsweb.org. The information is also available on the IAWA website http://www.iawawebsite.org or http://bio. kuleuven.be/sys/iawa/meetings.html, or the IUFRO website http://www.iufro.org/ events/calendar/current/. Deadline for registering without a late fee is May 1, 2010.

Further information and registration forms can be obtained from Fellow Regis Miller (rmiller1@wisc.edu).

John Barnett

Past President of IAWS 